Produto \& Produção, vol. 8, n. 3, p. 45-61, out. 2005

\title{
Sistemas de Informação e de Conhecimentos para contribuir na gestão municipal
}

\author{
Denis Alcides Rezende \\ Professor Doutor - PUCPR \\ Mestrado em Gestão Urbana \\ denis.rezende@pucpr.br \\ José Augusto Guagliardi \\ Professor Doutor da Universidade de São Paulo - USP/FEA \\ Mestrado em Gestão Urbana \\ jaguar@usp.br
}

Os Sistemas de Informação (SI) e a Tecnologia da Informação (TI) podem oferecer alternativas para apoiar os gestores municipais, fornecendo informações com qualidade e oportunas. Apenas as informações não são suficientes para resolverem os problemas dos municípios. Os gestores municipais também necessitam de conhecimentos personalizados e profícuos para suas atividades. A partir do capital intelectual das pessoas das prefeituras, os sistemas de conhecimentos (SC) podem armazenar, gerar e compartilhar seus conhecimentos peculiares e oportunos. O objetivo deste artigo é apresentar as teorias e as relações entre os SI, TI e SC, os preceitos da New Public Management, um modelo proposto de SC e seus respectivos produtos para aplicar em cidades e prefeituras. A metodologia de pesquisa é de natureza aplicada em estudos de casos brasileiros e americanos. Na conclusão são descritas as contribuições acadêmicas e organizacionais. Observa-se que o modelo proposto poderá contribuir na gestão municipal com maior qualidade, produtividade e efetividade.

Palavras-chave: sistemas de informação; sistemas conhecimentos; gestão municipal.

The Information System (IS) and the Information Technology (IT) can offer options to support municipal managers, supplying information with quality and opportunity. Only the information is not enough to solve municipal problems. The municipal managers also need personalized and useful knowledge for their activities. From people's intellectual capital of the prefectures (town hall), the Knowledge System (KS) can store, generate and share their peculiar and opportune knowledge. The objective of this paper is to introduce the theories and the relations among IS, IT and KS, the New Public Management precepts, the KS's proposal model and their respective products to apply in cities and prefectures. The research methodology is based in Brazilian and American case studies. In the conclusion are described the academic and company contributions. The KS's proposed model also can contribute in the municipal administration and consequently in the accomplishment of their goals, projects, strategies and public actions with wider quality, productivity and effectiveness.

Keywords: information system; knowledge system; municipal public administration.

\section{Introdução}

Diante das exigências fiscais, sociais, políticas e dos cidadãos, os municípios estão atualmente muito envolvidos em ambientes turbulentos, globalizados, competitivos e complexos. Isso evidencia uma realidade efetivamente relevante: a gestão municipal pública enfrenta a cada dia novos desafios para a atuação nos seus objetivos, projetos, estratégias e ações. Esses recentes desafios e transformações requerem novos e inovadores modelos públicos de gestão, assim como efetivos instrumentos, procedimen- tos e formas de ação, a fim de permitir que os gestores municipais tratem das mudanças contempladas pela sociedade globalizada.

Um desses novos e inovadores modelos públicos de gestão está relacionado com a nova gestão pública ou a new public management (NPM), que também requer informações e conhecimentos dos gestores municipais, dos servidores e dos munícipes ou cidadãos.

Os Sistemas de Informação (SI) e a Tecnologia da Informação (TI) podem oferecer alternativas para apoiar 
os gestores municipais, os servidores e os munícipes, fornecendo informações com qualidade e oportunas. Entretanto, apenas as informações não são suficientes para facilitar ou resolver por completo os problemas dos municípios. Essas pessoas também necessitam de conhecimentos personalizados e profícuos para suas atividades cotidianas, gerenciais e estratégicas. Nesse sentido, a partir do capital intelectual das pessoas das cidades e prefeituras, os Sistemas de Conhecimentos (SC) podem armazenar, gerar e compartilhar seus conhecimentos peculiares e oportunos.

Muitos problemas estão presentes nos municípios com a prestação de serviços públicos, onde os gestores e servidores municipais necessitam tomar decisões que envolvem muitos detalhes nas suas complexas atividades com servidores, empreiteiros, fornecedores, comunidades, cidadãos, atores sociais envolvidos e demais interessados (stakeholders).

O objetivo deste artigo é apresentar as teorias e as relações entre os SI, TI e SC, os preceitos da NPM, um modelo proposto de $\mathrm{SC}$ e seus respectivos produtos para aplicar em cidades e prefeituras. Também relaciona os SI, os SC e a gestão municipal. Sua relevância e seus resultados preliminares estão nos conhecimentos compartilhados pelos gestores municipais e potencialmente gerados pelo modelo proposto de SC que podem ser posteriormente armazenados numa "base de conhecimentos" para uso por todos nas cidades e nas prefeituras.

\section{Sistemas de Informação e Tecnologia da Informação}

Este capítulo fundamenta os conceitos relacionados com o tema abordado.

\subsection{Sistemas de Informação}

Os sistemas de informação podem ser entendidos como o conjunto de partes que interagem entre si, integrando-se para armazenar dados e gerar informações para contribuir nas decisões. Quando utilizam a tecnologia da informação, é o conjunto de software, hardware, recursos humanos e respectivos procedimentos que antecedem e sucedem o software (ALTER, 1996; STAIR, 1998; REZENDE, 1999).

Os sistemas de informação coletam, processam, armazenam, analisam e disseminam informações com um determinado objetivo. Incluem entradas, processamento e saídas. Podem ser formais ou informais. Baseados em computadores ou não (TURBAN; MCLEAN; WETHERBE, 1996).
Genericamente, os Sistemas de Informação (SI) podem ser classificados em nível operacional, gerencial e estratégico (STAIR, 1998; LAUDON e LAUDON, 1999; O'BRIEN, 2001; REZENDE, 2005).

Os Sistemas de Informação Operacionais (SIO) também são chamados de Sistemas de Apoio às Operações Organizacionais, Sistemas de Controle ou Sistemas de Processamento de Transações. Contemplam o processamento de operações e transações rotineiras quotidianas, em seu detalhe, incluindo seus respectivos procedimentos. Controlam os dados detalhados das operações das funções organizacionais imprescindíveis ao funcionamento harmônico das cidades, prefeituras e organizações (privadas ou públicas), auxiliando a tomada de decisão do corpo técnico ou operacional das unidades departamentais. Como exemplos, enquadram-se nessa classificação os pormenores e as minúcias dos SIO de: planejamento e controle de produção (com as informações: nome do produto, data da produção); faturamento (com as informações: nome do item de venda, preço do item, data de faturamento); contas a pagar e a receber (com as informações: valor do título, data de vencimento); estoque (com as informações: código do material, tipo de material); folha de pagamento (com as informações: valor do salário, valor do provento, nome do funcionário); contabilidade fiscal (com as informações: valor do lançamento, natureza do lançamento). Reiterando, nos SIO as informações são apresentadas no menor nível, ou seja, analíticas, detalhadas, e apresentadas no tempo gramatical singular. Esses sistemas são os mais estudados e trabalhados em geral. Eles são a parte central da maioria dos sistemas de informação das cidades, prefeituras e organizações (privadas ou públicas), contemplando todos os componentes básicos de funcionamento operacional das mesmas.

\section{Os Sistemas de Informação Gerenciais (SIG) são} também são chamados de Sistemas de Apoio à Gestão Organizacional ou Sistemas Gerenciais. Ainda, são conhecidos por sua sigla em inglês MIS (management information systems). Contemplam o processamento de grupos de dados das operações e transações operacionais, transformando-os em informações agrupadas para gestão. Trabalham com os dados agrupados (ou sintetizados) das operações das funções organizacionais, auxiliando na tomada de decisão do corpo gestor (nível médio ou gerencial) das unidades departamentais, em sinergia com as demais unidades. Resumindo, é todo e qualquer sistema que manipula informações agrupadas para contribuir para o corpo gestor da prefeitura ou da organização privada ou pública. Como exemplos, enquadram-se nessa classificação os grupos de informação dos SIG de: planejamento e controle de produção (com as informações: 
total da quantidade de peças produzidas, número de peças defeituosas); faturamento (com as informações: valor do faturamento do dia, valor acumulado do mês); contas a pagar e a receber (com as informações: número de títulos a pagar do dia, número de inadimplentes); estoque (com as informações: percentuais de estoque distribuídos por grupo de materiais, quantidade de peças disponíveis); folha de pagamento (com as informações: valor acumulado de salários, valor dos encargos sociais); contabilidade fiscal (com as informações: valor acumulado de impostos a recolher por mês, valor total dos tributos). Reiterando, nos SIG as informações são apresentadas em grupos, ou sintetizadas, tais como totais, percentuais, acumuladores, e normalmente apresentadas no tempo gramatical plural.

Os Sistemas de Informação Estratégicos (SIE) também são chamados de Sistemas de Informação Executivos ou Sistemas de Suporte à Decisão Estratégica. Ainda, são conhecidos por sua sigla em inglês EIS (executive information systems). Contemplam o processamento de grupos de dados das atividades operacionais e transações gerenciais, transformando-os em informações estratégicas. Trabalham com os dados no nível macro, filtrados das operações das funções organizacionais, considerando, ainda, os meios ambientes internos ou externos, visando auxiliar o processo de tomada de decisão da alta administração da prefeitura ou da organização privada ou pública. Habitualmente, os SIE possuem informações nas formas gráficas, amigáveis e normalmente on line, observando as particularidades de cada prefeitura ou organização e, ainda, com opção de descer no nível de detalhe da informação. Como exemplos, enquadram-se nessa classificação, com base nas informações operacionais e gerenciais, as relações, influências e decisões entre as seguintes informações: quantidade produzida versus quantidade de pedidos em negociação; valor do faturamento versus valor das contas a pagar; datas do planejamento de compras versus quantidade disponível no estoque; valor bruto da folha de pagamento, dos encargos sociais e dos impostos versus valor líquido do fluxo de caixa; valor da receita da prefeitura ou organização versus valor da receita do concorrente; quantidade de linhas de produção versus percentual de satisfação do cliente; valor dos custos em relação ao retorno versus valor do orçamento e da análise financeira; datas de prioridades de pagamento de juros versus datas dos descontos a clientes; valor da receita bruta da prefeitura ou organização versus valor da receita bruta da concorrência. Reiterando, nos SIE as informações são apresentadas de forma macro, sempre relacionadas com o meio ambiente interno (funções municipais ou organizacionais) ou externo da prefeitura ou organização privada ou pública (FURLAN et al., 1994; FREITAS et al., 1997; REZENDE, 2005).

Os sistemas de informações podem ser representados por um modelo dinâmico onde na prática não existem separações entre seus níveis (Figura 1). Outros destaques ou evoluções são as informações oportunas geradas e a base de dados única. Informações oportunas são informações geradas de forma completa, com qualidade e antecipadas. Base de dados única implica na eliminação de redundâncias de dados em todas as cidades, prefeituras e organizações (privadas ou públicas). Esse dinamismo implica prover o alinhamento, a coerência ou a sinergia das informações, fazendo com que todos na cidade, prefeitura e organização (privada ou pública) sejam envolvidos e direcionados no negócio privado ou serviço público, na competitividade e inteligência organizacional.

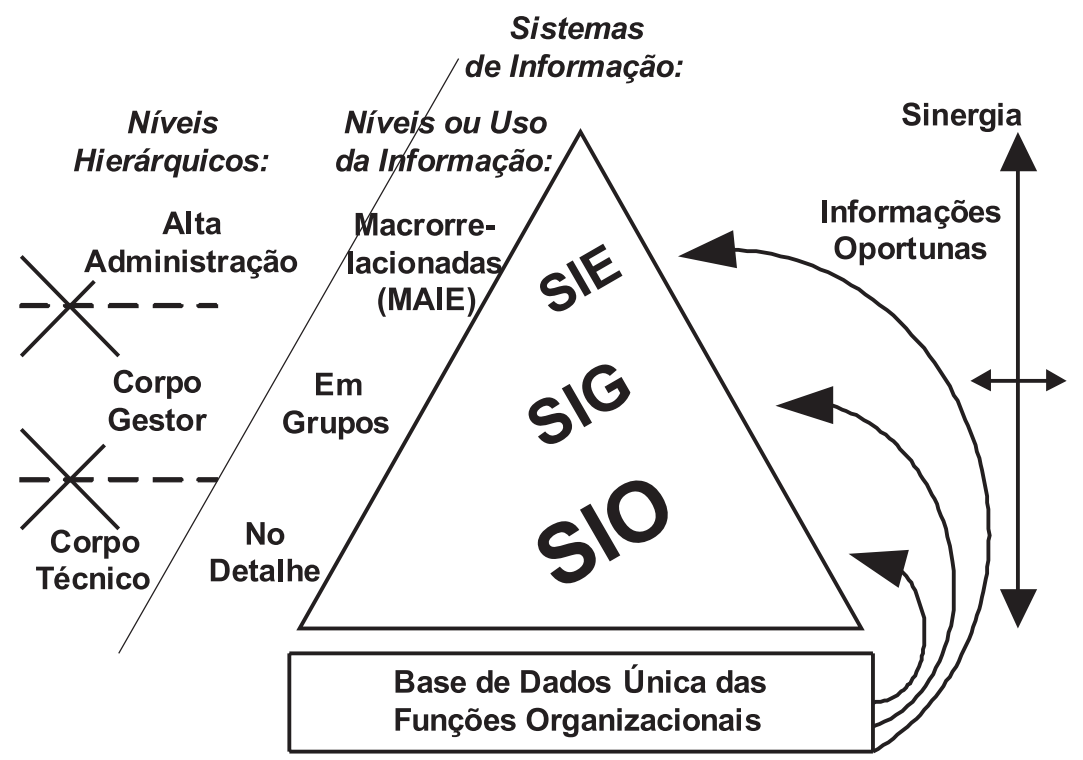

Figura 1 - Modelo dinâmico de sistemas de informação (REZENDE, 2005) 
A seleção dos dados para serem incluídos na base de dados única deve ser criteriosamente realizada. Para geração das informações oportunas é de fundamental importância o levantamento, a triagem, a análise e a avaliação da necessidade dos dados, pois caso contrário, as informações geradas podem ser inoportunas. No modelo dinâmico, as informações oportunas podem contribuir significativamente com a inteligência empresarial ou organizacional (REZENDE e ABREU, 2003; REZENDE, 2005).

\subsection{Modelos de informações organizacionais}

Os Modelos de Informações Organizacionais (MIO) descrevem todas as informações necessárias para gestão das cidades, prefeituras e organizações (privadas ou públicas). As informações devem ser relatadas nos níveis operacional, gerencial e estratégico. Esses modelos visam facilitar a aquisição de SI, contribuir nas atividades de planejamento de informações, auxiliar o desenvolvimento de SI com ou sem parcerias de soluções externas e na avaliação de pacotes de SI. Os MIO estão focados nas informações necessárias para gerir os negócios empresariais ou os objetivos organizacionais municipais, onde serão relatadas as informações estratégicas (macro relacionadas com o meio ambiente interno e externo), gerenciais (agrupadas, sintetizadas, totais, percentuais, acumuladores, plurais) e operacionais (no detalhe ou analítica) (REZENDE, 1999).

A informação e seus respectivos sistemas desempenham papel estratégico nas cidades, prefeituras e organizações (privadas ou públicas), a informação apresenta-se como recurso estratégico sob a óptica da vantagem competitiva e da inteligência organizacional (FREITAS et al., 1997; REZENDE e ABREU, 2003).
No documento do modelo de informações organizacionais são descritas apenas as informações. Em outro documento devem ser elaboradas as ações e descritos os procedimentos de como construir as respectivas informações necessárias. Nesse caso, a ênfase não está na ação, nos processos ou nos requisitos funcionais.

Como exemplo, pode-se modelar e estruturar as informações conforme o quadro da Figura 2.

No Quadro 1 fica exemplificado que por meio do Modelo de Informações Organizacionais ou por meio da estruturação de informações e posterior cruzamento das mesmas é possível subsidiar os gestores municipais, os servidores e os munícipes com informações necessárias para as corretas e oportunas decisões. Desse modo, percebe-se que na ausência dessas informações sistematizadas não há como decidir com base em dados reais.

No quadro da Figura 3 pode ser observado mais um exemplo de informações modeladas para projetos municipais.

Dessa forma, um efetivo sistema de informação (por mais simples que seja) pode proporcionar facilidade às pessoas que necessitam de determinadas informações para tomar decisões profícuas, o que pode garantir a efetividade em eventuais intervenções.

É importante ressaltar o princípio da sinergia (coerência ou integração) entre as informações. As informações devem ser integradas nos seus níveis (operacional, gerencial e estratégico), ou seja, para se obter as informações gerenciais e estratégicas, as informações operacionais no detalhe devem existir. As informações operacionais são transformadas em dados que deverão estar armazenados nas respectivas bases de dados

\begin{tabular}{|c|l|}
\hline Informações Estratégicas & $\begin{array}{l}\text { Quantidade de pessoas versus Quantidade de atendimento das } \\
\text { linhas de ônibus atuais. } \\
\text { Números de necessidades de reestruturação versus Percentual de } \\
\text { crescimento populacional por setor. }\end{array}$ \\
\hline \multirow{5}{*}{ Informações Gerenciais } & $\begin{array}{l}\text { Quantidade de atendimento das linhas de ônibus atuais. } \\
\text { Percentual de crescimento populacional por setor. } \\
\text { Número de bairros. } \\
\text { Número de ruas. } \\
\text { Número de linhas de ônibus. } \\
\text { Quantidade de pessoas do bairro. } \\
\text { Número de habitações com autorização para construção. }\end{array}$ \\
\hline & $\begin{array}{l}\text { Nome da rua nova. } \\
\text { Nome do novo bairro. } \\
\text { Nome da pessoa do bairro. } \\
\text { Nome da linha de ônibus. } \\
\text { Nome do serviço preferido do cidadão. }\end{array}$ \\
\hline
\end{tabular}

Figura 2 - Primeiro exemplo de modelo de informações organizacionais 


\begin{tabular}{|c|l|}
\hline Informações Estratégicas & $\begin{array}{l}\text { Quantidade de projetos elaborados versus Valor total do projeto. } \\
\text { Número de dias trabalhados no projeto versus Número de dias } \\
\text { parados. }\end{array}$ \\
\hline Informações Gerenciais & $\begin{array}{l}\text { Quantidade de projetos elaborados. } \\
\text { Valor total do projeto. } \\
\text { Número de dias trabalhados no projeto. }\end{array}$ \\
\hline Informações Operacionais & $\begin{array}{l}\text { Nome do projeto. } \\
\text { Nome da cidade cliente do projeto. } \\
\text { Tipo de projeto (A, B, X, Y). } \\
\text { Data de início do projeto. Data de término do projeto. }\end{array}$ \\
\hline
\end{tabular}

Figura 3 - Segundo exemplo de modelo de informações organizacionais

quando do uso de software nos sistemas de informação.

O MIO pode conter informações integradas dos seguintes tipos: convencional (trivial), personalizada e oportuna. Esses dois últimos tipos de informação, também chamadas de informações executivas ou inteligentes, facilitam o mapeamento dos conhecimentos organizacionais.

$\mathrm{Na}$ fase inicial dos projetos de planejamento, desenvolvimento ou aquisição de sistemas de informação, basta apenas relatar as informações necessárias, o que significa responder à seguinte pergunta: quais são as informações necessárias para gerir determinado negócio privado (ou módulos de uma função organizacional) ou para gerir uma atividade pública? Nas fases seguintes do projeto, ou seja, na sua elaboração propriamente dita, será necessário ainda responder a mais essas duas perguntas: como são construídas (elaboradas) as informações? Como são apresentadas (mostradas) as informações? A primeira diz respeito às fórmulas ou aos cálculos (algoritmos no caso de software) e a descrição detalhada (passo a passo) de como chegar à informação para ser disponibilizada ao seu usuário. A última pergunta diz respeito a como serão apresentadas as informações nos documentos (relatórios) ou nas telas dos sistemas de informação com suas respectivas máscaras ou leiaute (REZENDE, 2005).

\subsection{Tecnologia da Informação}

A Tecnologia da Informação (TI) pode ser conceituada como recursos tecnológicos e computacionais para guarda, geração e uso da informação (STAIR, 1998; REZENDE, 1999). Está fundamentada nos seguintes componentes: hardware e seus dispositivos e periféricos; software e seus recursos; sistemas de telecomunicações; gestão de dados e informações.

Em uma definição mais restrita, diz respeito ao aspecto tecnológico de um sistema de informação. Porém, às vezes o termo TI também é usado para denominar um sistema de informação. O termo pode até mesmo ser usado em um sentido mais amplo para descrever um conjunto de diversos sistemas de informação, usuários e gestão de uma organização inteira (TURBAN, McLEAN e WETHERBE, 1996).

A TI é a preparação, coleta, transporte e recuperação, armazenamento, acesso, apresentação e transformação de informações em todas as suas formas (voz, gráfico, texto, vídeo, imagem e outras) a partir dos seus componentes (BOAR, 1993).

Como um dos componentes da TI, os sistemas de telecomunicações e seus respectivos recursos são subsistemas especiais dos sistemas de informação global das cidades, prefeituras e organizações (privadas ou públicas). As comunicações podem ser definidas como as transmissões de sinais por um meio qualquer, de um emissor para um receptor. As telecomunicações se referem à transmissão eletrônica de sinais para comunicações. As comunicações de dados são um subconjunto especializado de telecomunicações que se referem à coleta, processamento e distribuição eletrônica de dados, normalmente entre os dispositivos de hardware de computadores.

A gestão de dados e informações compreende as atividades de guarda e recuperação de dados, níveis e controle de acesso das informações (NORTON, 1996), requerendo para essa gestão um completo plano de contingência e um plano de segurança de dados e informações.

Todos estes componentes interagem e necessitam do componente fundamental que é o recurso humano, (peopleware ou humanware). Embora conceitualmente esse componente não faça parte da TI, sem ele esta tecnologia não teria funcionalidade e utilidade.

Para a efetiva gestão da TI é fundamental a análise de viabilidade (custos, benefícios mensuráveis, não mensuráveis, riscos e respectivos resultados). Deve contemplar, ainda, as óticas da realidade econômica, financeira e político-social das cidades, prefeituras e 
organizações (privadas ou públicas) com o estado da arte e o sucateamento das tecnologias disponíveis no mercado. O foco principal na análise desses extremos está na adequação à necessidade das cidades, prefeituras e organizações (privadas ou públicas). Além da análise de custos, benefícios, riscos e viabilidade, ainda será necessário dar atenção para mais estes itens: respeitar a legislação vigente, evitando a pirataria; estabelecer um plano de contingência para atender a eventuais deficiências de funcionamento; focar a competitividade e a inteligência empresarial ou organizacional e não a tecnologia propriamente dita; elaborar um plano de gestão da mudança decorrente da introdução da tecnologia no contexto organizacional.

Existe uma enorme variedade de tecnologias emergentes que se estabelecem rapidamente de forma definitiva em todos os tipos de atividades, quer sejam profissionais, domésticas, esportivas, de lazer e até mesmo religiosas. As cidades, prefeituras e organizações (privadas ou públicas) têm como opção a utilização de diversas tecnologias modernas que facilitam os processos de tomadas de decisões dos gestores municipais, servidores e munícipes, visando atender as suas necessidades de se tornar rentável, perene, competitiva, moderna, efetiva e que ofereça qualidade. Para efetiva geração e manipulação das informações, é necessária a utilização de recursos de tecnologia moderna e é praticamente impossível as cidades, prefeituras e organizações (privadas ou públicas) fazerem com que o funcionamento dos SI seja efetivo sem o uso dessas tecnologias (FURLAN et al., 1994; FREITAS et al., 1997; REZENDE e ABREU, 2003).

Os conceitos de sistemas de informação e de tecnologia da informação não são definitivos e também não são unânimes, alguns autores separam e outros unem as suas significações. Ambos os conceitos estão em mudanças constantes e podem envolver questões humanas e organizacionais. Ambas as abordagens podem facilitar as decisões, gerar fatores competitivos, assumir papéis estratégicos e permitir diferenciais nas organizações, por meio de seus modelos integrados (ROCKART e MORTON, 1984; McFARLAN, 1984; PORTER e MILLAR, 1985; BAKOS e TREACY, 1986; HENDERSON e VENKATRAMAN, 1993; CIBORRA, 1994; BROADBENT, WEILL e CLAIR, 1999; LUFTMAN eBRIER, 1999).

\subsection{Sistemas de Informação com Tecnologia da Informação}

Para dinamizar e efetivar os SI nas cidades, prefeituras e organizações (privadas ou públicas), a TI e seus recursos são inexoravelmente necessários. Para tanto, as cidades, prefeituras e organizações (privadas ou públicas) têm como opção a utilização de diversas tecnologias modernas.

O modelo de sistemas de informação com tecnologia da informação complementa o modelo dinâmico com a utilização dos recursos tecnológicos disponíveis no mercado. A idéia fundamental é a viabilização dos sistemas de informação por meio da tecnologia da informação, pois atualmente é praticamente impossível desenvolver e implantar sistemas de informação nas cidades, prefeituras e organizações (privadas ou públicas) sem o uso desses recursos tecnológicos. As diversas tecnologias modernas disponíveis podem facilitar o processo de tomada de decisão dos gestores municipais,

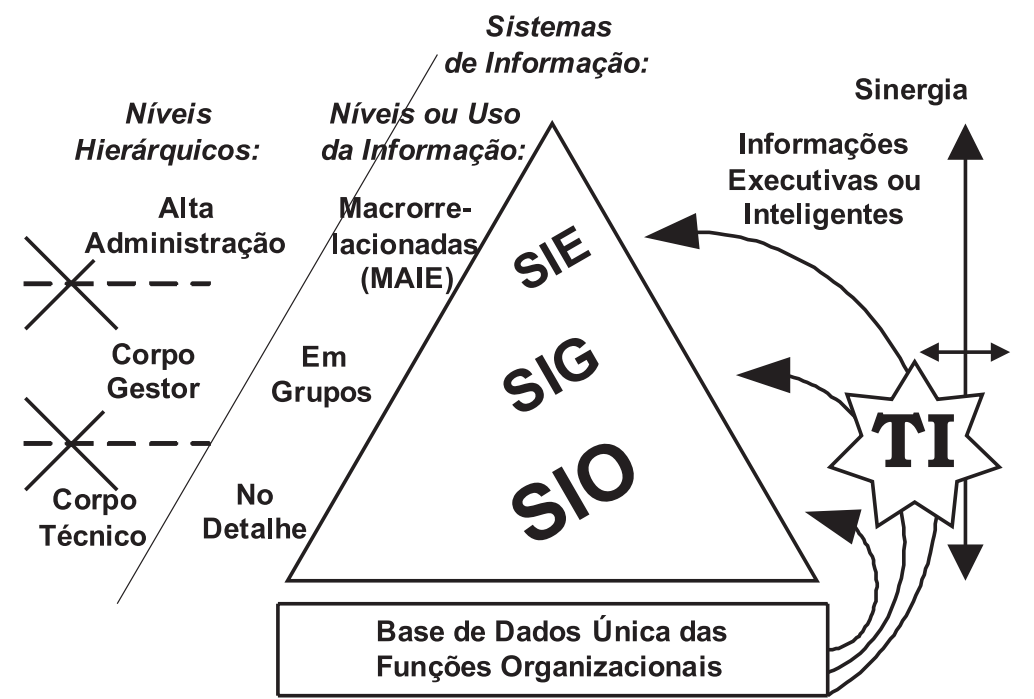

Figura 4 - Modelo de sistemas de informação com tecnologia da informação (REZENDE, 2005). 
os servidores e os munícipes, visando atender a sua complexidade, seu crescimento, sua modernidade, sua perenidade, rentabilidade, competitividade e inteligência. Numa abordagem mais prática e moderna, a informação deixa de estar dividida em estratégica, tática e operacional e passa a ser "executiva", transformando todos os usuários ou clientes das informações em executivos (REZENDE, 1999).

A tecnologia da informação permite a efetiva geração e a profícua manipulação das informações executivas ou "inteligentes", ou seja, informações oportunas e informações personalizadas (não apenas as triviais). A aplicação das tecnologias disponíveis no mercado nos sistemas de informação nas cidades, prefeituras e organizações (privadas ou públicas) têm como base os dois modelos anteriores. Todas as características do modelo dinâmico de sistemas de informação são contempladas nesse modelo proposto. $\mathrm{O}$ referido modelo pode ser graficamente representado pela Figura 4, onde a tecnologia da informação é destacada.

As principais TI aplicadas à geração de informações oportunas dos SI são: Executive Information Systems (EIS); Enterprise Resource Planning (ERP); Sistemas de Apoio a Decisões (SAD); Sistemas Gerenciadores de Banco de Dados (SGBD); Data Warehouse (DW); Recursos da Inteligência Artificial (IA); Sistemas Especialistas; Data Mining (DM); Database Marketing (DBM); recursos da Internet; automação de escritórios; recursos On-Line Analytic Processing (OLAP), On-Line Transaction Processing (OLTP), entre outras (STAIR, 1998; LAUDON e LAUDON, 1999; O’BRIEN; 2001; REZENDE e ABREU, 2003).

Essas tecnologias aplicadas são na sua maioria oriundas de conceitos anteriormente sedimentados pelas academias ou pelas organizações. Ou seja, primeiro surgiram os conceitos e posteriormente o respectivo software que preservou e contemplou os referidos preceitos originais.

O Executive Information Systems (EIS) é um tipo de sistema de informação e uma metodologia definida por Furlan et al. (1994). Com base nessa metodologia e respectivos conceitos pertinentes, pode-se desenvolver uma aplicação (software) de consulta às bases de dados das funções organizacionais para a apresentação de informações executivas e inteligentes de forma simples e amigável, atendendo às necessidades dos executivos da alta administração e do corpo gestor. Permite acompanhar os resultados diários das cidades, prefeituras e organizações (privadas ou públicas), tabulando dados de todas as funções organizacionais para depois exibi-los de forma gráfica e simplificada. Assim, essa ferramenta possui características de simplicidade de uso, de geração de gráficos e de utilização das bases de dados disponíveis. Para o funcionamento da tecnologia EIS nas cidades, prefeituras e organizações (privadas ou públicas) existem basicamente três alternativas. A primeira e mais trabalhosa das opções de funcionamento exige a digitação dos dados na base de dados do próprio EIS, para posterior geração das informações. A segunda alternativa exige a alimentação da base de dados do próprio EIS por meio de softwares paralelos executados por comandos em determinados momentos. A terceira opção de funcionamento é a mais indicada, pois faz o acesso automático e instantâneo às bases de dados existentes das funções organizacionais.

O Enterprise Resource Planning (ERP) corresponde aos pacotes (software) de gestão organizacional ou de sistemas integrados, com recursos de automação e informatização, visando contribuir originalmente para a gestão operacional das cidades, prefeituras e organizações (privadas ou públicas). Essa tecnologia tem a prerrogativa de utilizar o conceito de "base de dados única”, pois todos os seus módulos ou subsistemas estão num único software. Ela também oferece, na maioria dos casos, um EIS como opção integrada. Essa tecnologia pressupõe realizar de forma integrada todas as atividades de todas as funções organizacionais e é fortalecida por sua retaguarda, onde estão os "processos integrados" e não simplesmente as interfaces de integração, favorecendo a ligação efetiva dos dados e refletindo com exatidão as informações executivas e inteligentes.

Os Sistemas de Apoio a Decisões (SAD) são tecnologias fundamentais para a evolução do processo de tomada de decisão nas cidades, prefeituras e organizações (privadas ou públicas) modernas e usuárias de informações executivas e inteligentes. Também são chamados de Decision Support Systems (DSS). Um SAD pode ser composto de: banco de dados e seu sistema gerenciador; banco de modelos e seu sistema gerenciador com um motor de inferência; software gerenciador de interface.

O Banco de Dados (BD) pode ser uma coleção de dados organizada como num arquivo convencional. Quando essa tecnologia é convencional, possui um campo chamado de "chave" ou "índice" usado para identificar e acessar os registros do mesmo. Já um Sistema Gerenciador de Banco de Dados (SGBD) permite que os dados sejam armazenados em um só lugar, possibilitando a manipulação dos dados por diferentes recursos tecnológicos de interface. Também é conhecido como database management system (DMS). Possui três componentes básicos: linguagem de definição de dados, linguagem de manipulação de dados e dicionário de dados. 
O Data Warehouse (DW) pode ser um grande banco de dados que armazena dados de diversas fontes para futura geração de informações integradas, com base nos dados do funcionamento das funções organizacionais operacionais das cidades, prefeituras e organizações (privadas ou públicas). É um banco de dados que consolida dados extraídos de diversos sistemas de informação em um grande banco de dados que pode ser utilizado para gerar informações executivas e inteligentes, a partir de reorganizações de dados e combinações de diversas informações.

A Inteligência Artificial (IA) pode plenamente ser aplicada como tecnologia de funcionamento dos sistemas de informação, por meio de seus recursos, tais como os sistemas especialistas, data mining e demais ferramentas e algoritmos. A expressão inteligência artificial pode ser generalizada como a simulação da "inteligência humana", na realização de atividades elaboradas por pessoas, que podem ser substituídas pelo uso dos recursos da ciência da computação e seus respectivos algoritmos inteligentes.

Os Sistemas Especialistas (expert systems) estão direcionados para a solução de problemas que normalmente são resolvidos por "especialistas" humanos. Para tanto, esses sistemas precisam acessar uma substancial base de conhecimentos do domínio da aplicação, com diversificados mecanismos de raciocínio baseados em regras predefinidas.

O Data Mining (DM) pressupõe a manipulação de um grande volume de dados permitindo "mineração" de dados, a fim de gerar um real valor ao dado, transformando-o em informação e conhecimento. Esta tecnologia é formada por um conjunto de ferramentas que, por meio do uso de algoritmos de aprendizado ou baseados em redes neurais e em estatísticas, são capazes de explorar um grande conjunto de dados, extraindo conhecimentos na forma de hipóteses e de regras.

Os Sistemas de Telecomunicações e seus recursos são imprescindíveis para o funcionamento dos sistemas de informação, pois a grande maioria das cidades, prefeituras e organizações (privadas ou públicas) têm mais de um software e hardware, necessitando da telecomunicação entre os mesmos, estando fisicamente próximos ou em múltiplos e distantes locais.

Os recursos da internet (a rede mundial de comunicações), juntamente com a intranet (quando se refere ao meio interno das cidades, prefeituras e organizações) e extranet (quando se conectam redes distintas em longa distância ou externas) podem contribuir com gestão municipal. Ela pode ser utilizada juntamente com a valorização do ser humano e da adaptação de seus sistemas de informação para captação, tratamento, distribuição, disseminação e troca de informação no ambiente Internet e seus recursos.

A automação de escritórios está direcionada para o uso das informações em escritórios e suporte nas atividades de gestão e de comunicação. Esta tecnologia está focada nas atividades de gestão de documentos, projetos, comunicação eletrônica, groupware e agendas. Tem como objetivo facilitar a geração de informações executivas e inteligentes para a tomada de decisão. Outras formas de automação podem ser utilizadas em determinadas organizações, tais como bancária, comercial e industrial.

Todas as tecnologias emergentes aplicadas à geração de informações podem trabalhar juntamente com os recursos On-Line Analytic Processing (OLAP) e OnLine Transaction Processing (OLTP). As tecnologias e seus recursos OLAP e OLTP constituem-se em uma recente abordagem do que se pode fazer com relação aos Sistemas de Informação como suporte à tomada de decisão. O recurso OLTP suporta as operações quotidianas das cidades, prefeituras e organizações (privadas ou públicas) por meio de processamento operacional, e o OLAP suporta a análise da tendência, os cenários e as projeções das organizações, como instrumento de suporte às decisões. Enquanto o OLTP trabalha com dados que movimentam as organizações em tempo real, o OLAP trabalha com dados históricos, a fim de gerar informações e conhecimentos para analisar as organizações. O OLTP tem a função de alimentar a base de dados que o OLAP utilizará para a transformação do conteúdo em informações e conhecimentos úteis para toda a cidade, prefeitura e organização (privada ou pública).

O Database Marketing (DM) pode ser entendido como recursos da tecnologia da informação e seus componentes a serviço das atividades de marketing das cidades, prefeituras e organizações (privadas ou públicas) e respectivas informações executivas e inteligentes geradas com base nesses recursos. É uma tecnologia que envolve necessariamente um sistema de banco de dados computadorizado, gerando informações em tempo real. E, para tanto, são necessários software, hardware, sistemas de telecomunicação e respectivos modelos de gestão de dados e informações.

As tecnologias normalmente são resultados de "filosofias" ou conceitos entendidos e aceitos pelas cidades, prefeituras e organizações (privadas ou públicas) e seus respectivos gestores municipais, os servidores e os munícipes, oriundos ou não de modelos de administração e gestão moderna. Nesses casos, surgem primeiro os conceitos e depois as aplicações com os recursos da tecnologia da informação aplicada. Como exemplos, podem ser citados os seguintes conceitos ou filosofias de gestão: CRM - Customer Relationship Management 
(Gestão das Relações com o Consumidor); SCM Supply Chain Management (Gestão da Cadeia de Suprimentos); BSC - Balanced Scorecard (Perspectivas do cliente, financeira, de processos internos e de aprendizado ou conhecimento organizacional); ECC-Enterprise Core Competence (Competências Essenciais da Empresa); BI - Business Intelligence (Inteligência de Negócios) e diversas outras (REZENDE e ABREU, 2003).

Para as cidades e prefeituras as tecnologias aplicadas estão direcionadas para o governo eletrônico (e-government) que pode ser contemplado nos modelos das Figuras 2 e 3. O governo eletrônico (e-gov) pode ser entendido como a aplicação dos recursos da TI na gestão pública e política das organizações desse tipo. Os termos "governança e democracia eletrônica" têm foco no uso das tecnologias de informação e comunicação (TIC) aplicadas às atividades e ações de governo, seja de governo para governo ou em especial, de governo para com a sociedade e seus cidadãos (CUNHA, 2000; REZENDE, 2005). Pela implementação continuada de redes de computadores, softwares e bancos de dados, web browsers e portais, os cidadãos obtêm informações que podem ser compartilhadas de forma oportuna. As aplicações ou serviços real-time se tornam mais operáveis e consistentes, estabelecendo uma maior conectividade entre os cidadãos e o governo e resultando na melhoria da responsabilidade e transparência da gestão urbana (WAISANEN, 2002). O termo governo eletrônico tem foco no uso das novas tecnologias de informação e comunicação aplicadas em todas as funções de governo e deste para com a sociedade (HEEKS, 2001; RUEDIGER, 2002; RILEY, 2003).

Todas essas tecnologias podem favorecer a gestão do conhecimento quando aplicadas nos sistemas de informação e nos sistemas de conhecimentos. As informações geradas e os conhecimentos vinculados com esses sistemas podem facilitar a gestão municipal das cidades.

\section{Gestão Municipal}

O conceito de gestão, sob a ótica da administração, está relacionado com o conjunto de recursos decisórios e a aplicação das atividades destinadas aos atos de gerir (MINTZBERG e QUINN, 2001). Em termos gerais, a governança pode ser entendida como a competência dos gestores nas atividades e nas ações de gestão.

Os conceitos de gestão municipal, de gestão urbana e de governança pública estão integrados e se complementam. A governança pública está direcionada com a capacidade dos governos na gestão das funções federais, estaduais e municipais, bem como com a competência na implementação de respectivas políticas públicas para facilitar as ações necessárias na condução do país, dos estados e das cidades, contextualizando a participação dos cidadãos nesses desafios (CUNHA, 2000). A gestão urbana pode ser entendida como a gestão de cidades, principalmente no que diz respeito aos componentes do plano diretor de cidades. A gestão municipal está direcionada aos componentes do planejamento estratégico de cidades e também aos instrumentos de administração necessários nas atividades de gestão das prefeituras. A cidade é um organismo dinâmico e complexo que se caracteriza por grandes diversidades e múltiplos contrastes, gerando inúmeras dificuldades aos gestores municipais, servidores, munícipes e aos demais interessados no município (REZENDE e CASTOR, 2005).

A nova gestão pública ou a new public management (NPM) pressupõe aplicar nas organizações públicas os modelos de gestão originalmente oriundos da iniciativa privada e dos conceitos de administração estratégica focada nos negócios empresariais. Esse modelo para nova gerência pública apresenta como características: contextualizar o cidadão como um cliente em foco; dar o sentido claro da missão da organização pública; delegar autoridades; substituir normas por incentivos; elaborar orçamentos baseados em resultados; expor operações do governo à concorrência; procurar soluções de mercado e não apenas administrativas; e medir o sucesso do governo pelo cidadão. Também tem como princípios: reestruturação, reengenharia, reinvenção, realinhamento e reconceituação (JONES e THOMPSON, 2000). O novo gerenciamento é um largo campo de discussão sobre as intervenções políticas dentro do governo executivo. As características dos instrumentos das intervenções de políticas são regras institucionais e rotinas organizacionais que afetam o planejamento das despesas, a gestão das finanças, a administração pública, as relações civis de trabalho, as compras, a organização e os métodos, a auditoria e a avaliação (BARZELAY, 2001).

A NPM tem defendido que os gestores municipais devem se comportar como novos empresários, mais dedicados e crescentes em posturas de privatização do governo, não emulando apenas as práticas, mas também os valores dos negócios. Os proponentes da NPM desenvolveram seus amplos argumentos por contrastes com a velha administração pública (old public administration) em favor do "novo serviço público". Nesse novo serviço o papel primário do servidor público é ajudar os cidadãos na articulação e no encontro de seus interesses compartilhados no lugar de tentar controlar ou guiar sociedade. Como resultado, várias mudanças altamente positivas foram implementadas no setor público (DENHARDT e DENHARDT, 2000; OSBORNE e GAEBLER, 1992). A evolução do movimento da NPM acrescentou mais pressão nas burocracias para tornar as organizações 
públicas mais responsivas para os cidadãos como clientes. Sem dúvida, é um avanço importante na contemporânea administração pública (VIGODA, 2002).

A aplicação da NPM pode ser facilitada com o funcionamento do modelo proposto (Figura 3).

\section{Metodologia de pesquisa}

A metodologia de pesquisa empregada se constitui numa abordagem de natureza aplicada (ROESCH, 1999). Foi aplicada porque gerou conhecimentos novos e úteis para o avanço da ciência e para aplicação prática dirigidos à solução ou facilitação de problemas relativos aos objetivos propostos desse documento (MARCONI e LAKATOS, 1996).

O modelo proposto (Figura 3) está fortemente embasado em projetos acadêmicos e organizacionais desenvolvidos nos últimos anos pelos autores desse trabalho. Nos projetos acadêmicos de pesquisas num programa de mestrado, destacam-se os estudos de caso elaborados nas prefeituras de quatro municípios brasileiros e dois municípios americanos (YIN, 1994).

Contempla parcialmente conceitos da pesquisa exploratória no que tange ao levantamento bibliográfico e documental, requerendo ainda mais investigações futuras. Aproxima-se da pesquisa descritiva quando descreve a preocupação dos autores com a atuação prática das discussões relatadas na descrição do modelo proposto (Figura 3) (GIL, 1999).

Dessa forma, abrange uma visão de multimétodos para atender os objetivos propostos desse documento (NACHMIAS e NACHMIAS, 1987; GIL, 1999).

\section{Modelo proposto de Sistemas de Conhecimentos}

A possibilidade de acesso, uso e compartilhamento das informações oportunas e dos conhecimentos personalizados por todos nas cidades e prefeituras, facilitados pelos recursos emergentes da TI, seria equivalente à disseminação das melhores práticas das organizações públicas e privadas. Dessa forma, os resultados de análises, cenários, alertas, combinações e comparações entre informações oriundas da base de dados única seriam também equivalentes ao conhecimento, pois agregam valor as atividades municipais.

\subsection{Conhecimento}

O conhecimento das cidades, prefeituras e organizações (privadas ou públicas) também pode ser chamado de capital intelectual, competência, habilidade. Inteligên- cia empresarial ou organizacional é reconhecido como um ativo intangível de inestimável valor (STEWART, 1998; SVEIBY, 1998; DAVENPORT e PRUSAK, 1998).

A aquisição do conhecimento é um processo interno de compreensão das informações recebidas, que ocorre de forma diferente em cada indivíduo devido à existência de modelos mentais individuais, que podem resultar em ações e decisões completamente diferentes como resultados de um mesmo conjunto de dados (TURTHIL, 1990). O conhecimento também pode se visto como "uma capacidade de agir" e é contextual, não podendo ser destacado do ambiente (SVEIBY, 1998). Na visão oriental, a divisão cartesiana entre sujeito e objeto é rebatida, neste caso a criação do conhecimento ocorre de dentro para fora nas organizações, com o intuito de redefinir problemas e soluções procurando afetar seu ambiente (NONAKA e TAKEUCHI, 1997).

Sem fazer distinção entre tácito e explícito ou estabelecer duas dimensões para o conhecimento, ele é reconhecido como uma mistura de elementos formalmente estruturados e intuitivos. No caso do conhecimento intuitivo, sua representação e seu entendimento lógico são mais difíceis (DAVENPORT e PRUSAK, 1998). O conhecimento é uma derivação da informação manipulada a partir de dados. A geração do conhecimento ocorre quando as informações são comparadas, combinadas e analisadas por pessoas, principalmente quando utilizadas nos processos decisórios (PEREIRA et al., 2000; SANTOS et al., 2001).

A partir de todas essas abordagens a respeito de conhecimento, observa-se a necessidade de envolver pessoas, definir modelos de SI e de utilizar TI para a geração e gestão de sistemas de conhecimentos.

\subsection{Gestão do Conhecimento}

Com as dimensões estabelecidas para o conhecimento, a Gestão do Conhecimento (GC) pode ser entendida como uma forma de gestão ou administração, compartilhamento e aproveitamento do conhecimento das pessoas e disseminação das melhores práticas para o crescimento das organizações (PEREIRA et al., 2000; SANTOS et al., 2001; REZENDE, 2002). O conhecimento tácito tende a ser tanto localizado quanto renitente, não podendo ser encontrado nos livros, manuais ou bancos de dados - ele se dissemina quando as pessoas se encontram e trocam suas experiências, tornando-o explícito (NONAKA e TAKEUCHI, 1997; STEWART, 1998; DAVENPORT e PRUSAK, 1998).

A estratégia organizacional deve aplicar a GC como um componente das atividades das organizações (privadas ou públicas) procurando estabelecer uma 
ligação entre os ativos intelectuais das organizações. Tanto explícitos (registrados) como tácitos (pessoais) e os seus resultados obtidos em decorrência da disseminação das políticas e práticas em todos os níveis das organizações: operacional, gerencial e estratégico (BARCLAY e MURRAY, 1999).

Outro conceito de GC é apresentado como a arte de adicionar valor por meio da utilização dos ativos intangíveis. Desde a contratação de novos funcionários até os resultados obtidos por estes devem ser monitorados de forma poder-se incluir o valor destes ativos intangíveis nos balanços contábeis (SVEIBY, 1998).

Uma definição formal para a GC depende do ponto de vista adotado. Ela pode ser encarada como uma evolução da gestão da informação onde a maior preocupação está relacionada com as formas de armazenamento, seleção, compartilhamento e apresentação. Ou ainda, como um processo de aprendizado que deve ser gerido, isto é, a maneira com que as pessoas ensinam e aprendem as atividades nas cidades, prefeituras e organizações (PEREIRA et al., 2000).

Na prática, a GC consiste na identificação e mapeamento dos ativos intelectuais da cidade, prefeitura e organização (privada ou pública), divulgando e gerando novos conhecimentos para a vantagem competitiva e compartilhando as melhores práticas e tecnologias que impulsionarão estes processos.

\subsection{Bases e mapas de conhecimentos}

O conhecimento sempre é entendido como algo pessoal, pertencente aos indivíduos que compõem as cidades, prefeituras e organizações (privadas ou públicas). Portanto, existe a necessidade de se capturar, mapear e distribuir este conhecimento a todos e em todos os níveis das organizações para que efetivamente o conhecimento se torne uma vantagem competitiva e possibilite o crescimento e a perenidade das organizações (NONAKA e TAKEUCHI, 1997; STEWART, 1998; DAVENPORT e PRUSAK, 1998; SVEIBY, 1998).

As ferramentas disponíveis para a gestão dos sistemas de conhecimentos nas cidades, prefeituras e organizações são os SI. E quando esses SI utilizam as TI emergentes e os novos modelos de sistemas, permitem a administração adequada dos conhecimentos. Nessa proposta, as bases de conhecimentos se constituem no local onde são depositados conhecimentos expressos em dados não triviais, imagens, sons, raciocínios elaborados, percepções humanas, entre outras possibilidades (REZENDE, 2002).

Os Mapas de Conhecimentos (MC) descrevem todos os conhecimentos necessários para gestão de cidades, prefeituras e organizações (privadas ou públicas). Os conhecimentos podem ser relatados nos níveis operacional, gerencial e estratégico. Esses mapas visam facilitar a aquisição de SI, contribuir nas atividades de planejamento de informações e de conhecimentos, auxiliar o desenvolvimento de SC com ou sem parcerias de soluções externas e na avaliação de pacotes de SI. Os MC estão focados nos conhecimentos personalizados e oportunos necessários para gerir os negócios empresariais ou os objetivos organizacionais públicos (REZENDE, 2002).

\subsection{Sistemas de Conhecimentos}

Todo e qualquer sistema que manipula ou gera conhecimentos organizados para contribuir com os seres humanos, com as cidades, prefeituras e organizações (privadas ou públicas) e com a sociedade como um todo, pode ser chamado de Sistemas de Conhecimentos (SC) (REZENDE, 2002; REZENDE, 2005).

Os SC podem ser compostos pelos recursos emergentes da TI ou por simples softwares específicos, onde são gerados informações e conhecimentos agregados e personalizados. O que significa a difusão e compartilhamento das informações relevantes e úteis, "trabalhadas" por pessoas ou por recursos computacionais, produzidas com qualidade e de forma antecipada, transformando-as em conhecimento explícito, que possa ser utilizado por todas as pessoas das organizações, como suporte à obtenção da vantagem competitiva inteligente (NOLAN, 1993; DAVENPORT e PRUSAK, 1998; LAUDON e LAUDON, 1999; MARKUS, 2001).

As pessoas e suas competências e habilidades fazem com que os SC funcionem de fato como componentes responsáveis pela excelência das organizações bemsucedidas e pelo aporte de capital intelectual que simboliza a importância do fator humano contextualizadas. Os SC, os SI, a TI e as pessoas se constituem partes essenciais dos desenvolvimentos recentes das estratégias organizacionais baseadas em recursos e no conhecimento (FLEURY e OLIVEIRA Jr., 2001; JOÃO, 2001). Essa abordagem apresenta as pessoas e seus conhecimentos e capacitações como ativos estrategicamente relevantes e como competências essenciais para a vantagem competitiva e a inteligência empresarial ou organizacional (PRAHALAD e HAMEL, 1990; SANTOS et al., 2001). Os recursos que são internos estão direcionados para a melhoria do desempenho das cidades, prefeituras e organizações (privadas ou públicas) numa abordagem que propõe que os mesmos sejam os principais determinantes de sua competitividade inteligente. Nessa competitividade são contempladas as estratégias de criação, transferência, absorção e gestão do conhecimento, 
incluindo os preceitos da inovação.

A inovação pressupõe um processo formal não só para criar novas idéias, mas também para fazer diferentes determinadas atividades, produtos ou serviços (TORNATZKY eFLEISCHER, 1990).

Os SC se constituem em relevante e inovadora ferramenta para auxiliar a gestão das cidades, prefeituras e organizações (privadas ou públicas).

\subsection{Sistemas de Conhecimentos com Tecnologia da Informação}

Para que as cidades, prefeituras e organizações (privadas ou públicas) obtenham as vantagens e utilidades efetivas dos SC, é exigido o emprego e a integração dos recursos da TI. Essa integração pode ser observada no modelo proposto da Figura 5. Os SI operacionais, gerenciais e estratégicos manipulam e geram as respectivas informações oportunas a partir da base de dados única. Essas informações são respectivamente apresentadas no detalhe, agrupadas e macrorrelacionadas com o meio ambiente interno ou externo das cidades, prefeituras e organizações.

Os SC manipulam e geram conhecimentos a partir das bases de conhecimentos. Os conhecimentos são oriundos da base de dados única e do meio ambiente interno e externo as cidades, prefeituras e organizações (privadas ou públicas). Em ambas as bases (de dados única e de conhecimentos) são criadas e acionadas por meio dos recursos da TI.
Os recursos e os componentes da TI são os responsáveis pelas atividades de geração, troca e integração (sinergia) dos dados, informações e conhecimentos. Toda a sinergia desses sistemas é trabalhada pelos servidores municipais, técnicos e gestores das cidades, prefeituras e organizações (privadas ou públicas) com seus respectivos capitais intelectuais, competências, habilidades e conhecimentos tácitos e explícitos.

Além das tecnologias da informação aplicadas à geração de informações oportunas, tais como, EIS, ERP, SAD, SGBD, IA, OLAP e OLTP, existem outras que são mais direcionadas a geração e gestão de sistemas de conhecimentos. Dessas tecnologias, destacam-se: ferramentas baseadas na Internet e portais; mapas de conhecimentos; gerenciamento eletrônico de documentos; groupware; workflow e automação de processos; bases inteligentes de conhecimento; sistemas especialistas; software de business intelligence; ferramentas de apoio à inovação e produtos (CARVALHO, 2000).

Por outro lado, qualquer software específico desenvolvido em linguagens convencionais de programação também pode cumprir esse papel. Nesse contexto, também podem estar incluídas as aplicações do e-government das cidades e das prefeituras.

\section{Relações entre os Sistemas de Informação, Sistemas de Conhecimentos e a Gestão Municipal}

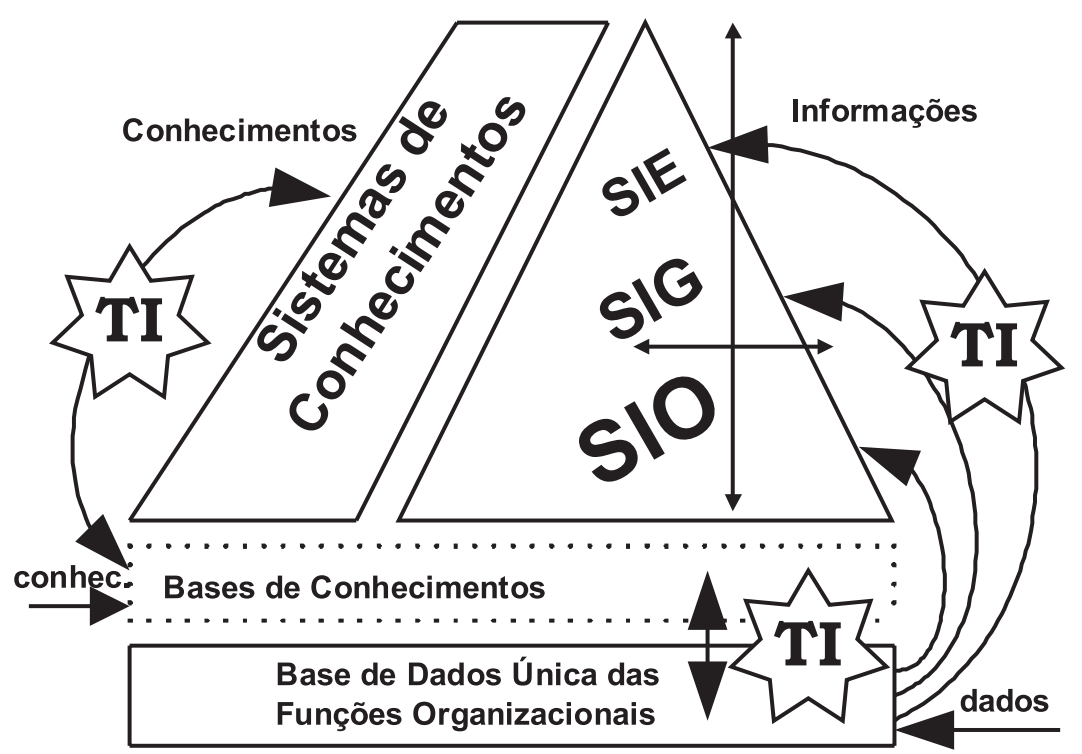

Figura 5 - Modelo de integração dos Sistemas de Conhecimentos com SI e TI (REZENDE, 2005) 
Os sistemas de informação e os sistemas de conhecimentos (e respectivas tecnologias da informação) podem estar diretamente relacionados com a gestão municipal. Esses sistemas (juntamente com os modelos de informações e os mapas de conhecimentos) podem se constituir em instrumentos inovadores nas cidades e prefeituras. Principalmente à medida em que podem oferecer informações oportunas e conhecimentos personalizados sobre o município para os gestores municipais, servidores e munícipes e para toda a comunidade local decidirem coletivamente e agirem mais efetivamente.

A gestão do município desafia a administração municipal moderna quando exige o equilíbrio dos diferentes interesses envolvidos. Tal como o desenvolvimento dos sistemas, o desenvolvimento do município deve estar integrado com as estratégias da gestão municipal, com a vocação e o potencial da cidade. Ambos os desenvolvimentos fazem parte dos processos estratégicos relacionados ao planejamento e a renovação do espaço urbano.

As relações entre essas variáveis (sistemas de informação, sistemas de conhecimentos e gestão municipal) também estão expressas nos movimentos econômicos, financeiros, políticos e sociais do município. De forma similar aos processos de desenvolvimento do município, o processo de desenvolvimento dos sistemas de informação e dos sistemas de conhecimentos também deve ser elaborado em partes metodologicamente integradas. Essas partes ou fases devem ser desmembradas em subfases onde pelo menos um produto deve ser gerado em cada uma delas. Os produtos gerados devem ser aprovados por uma equipe multidisciplinar, conselho da cidade ou comitê participativo com pessoas que dominam o tema municipal e seus pormenores desafiadores.

Os modelos de informações organizacionais e os mapas de conhecimentos (que fazem parte do modelo proposto na Figura 3) podem expressar a necessidade de informações e de conhecimentos requeridos pelos decisores (gestores municipais, servidores e munícipes) para fins de planejamento e gestão do município. Nesses modelos podem ser descritas inúmeras informações tais como: valores, números, índices, indicadores, percentuais, quantidades, coeficientes, taxas e outras informações da cidade ou da prefeitura.

Além dessas informações (triviais, oportunas e personalizadas), os referidos modelos e mapas também podem relatar diversos conhecimentos tais como: percepções dos gestores municipais, servidores e munícipes; idéias de ações; concepções de necessidade de recursos; entendimentos para negociações e parcerias público- privadas; observações de possíveis causas dos problemas atuais; percepção de um problema futuro; entendimentos de cenários previstos; e diversos outros conhecimentos inerentes a cidades e a prefeituras. Todas essas e outras informações e conhecimentos devem ser direcionados aos problemas e às soluções pertinentes ao município.

A grande maioria das informações e dos conhecimentos da gestão municipal está relacionada com as funções municipais: serviços municipais, marketing, financeira, materiais ou logística, recursos humanos e jurídicolegal.

A função municipal serviços municipais pode contemplar informações e conhecimentos desses módulos: serviços municipais específicos (educação, saúde, segurança, transporte, abastecimento, esporte, social, cultura, habitação, meio ambiente, obras, turismo, entre diversas outras); planejamento, engenharia, controle e monitoramento de projetos municipais; sistemas de qualidade, produtividade, efetividade e sustentabilidade dos serviços municipais; sistemas de indicadores locais; sistemas ou grupos regulamentadores (governo federal, governo estadual, órgãos especiais, sindicatos, conselhos, associações, etc.). Essa função é chamada de função primária ou principal. Ela é essencial para funcionamento e gestão da cidade. É a mais abrangente em termos de análise, para tanto, atenção especial deve ser dispensada a ela e seus módulos ou sistemas.

A função municipal marketing pode contemplar informações e conhecimentos desses módulos: planejamento e gestão de marketing municipal; sistema de imagem institucional; gestão de munícipes; projetos de marketing social; gestão de contratos de marketing; pesquisas e estatísticas.

A função municipal financeira pode contemplar informações e conhecimentos desses módulos: despesas ou contas a pagar; receitas ou contas a receber; fundos municipais, estaduais e federais; movimentos bancários; fluxo de caixa; orçamentos municipais; administração do capital; e análise de custos, benefícios (mensuráveis e não mensuráveis), riscos e viabilidades (econômicofinanceira, técnica, legal, ambientais, culturais, motivacionais, políticas, etc.).

A função municipal materiais ou logística pode contemplar informações e conhecimentos desses módulos: fornecedores; compras ou suprimentos; estoque; transporte; recepção e expedição de materiais; e importação.

A função municipal recursos humanos pode contemplar informações e conhecimentos desses módulos: recrutamento e seleção; administração de pessoal, 
férias, admissão e demissão; folha de pagamento; cargos e salários; treinamento e desenvolvimento (capacitação); benefícios e assistência social; segurança e medicina do trabalho.

A função municipal jurídico-legal pode contemplar informações e conhecimentos desses módulos: contabilidade; impostos e recolhimentos; ativo fixo ou patrimônio; livros fiscais de entrada e saída.

Todas as funções municipais podem incluir as aplicações do e-government quando utilizam os recursos das Tecnologias da Informação (ou Tecnologia da Informação e Comunicação - TIC) nas atividades da cidade e ações da prefeitura.

Outro exemplo para fortalecer as relações entre os sistemas de informação, os sistemas de conhecimentos e a gestão municipal são as atividades dos engenheiros gestores de obras municipais. Os engenheiros gestores concebem constantemente novos conhecimentos personalizados e peculiares sobre as obras municipais, tais como: percepção da dificuldade de reversão de prejuízo futuro de uma obra; idéias de ações que podem ser tomadas em virtude do cenário atual, com base em experiências semelhantes anteriores; concepção de quais equipamentos, materiais, serviços e funcionários, são vitais para a obra; entendimento de quais contratos ativos podem ser negociados, visando adequação à realidade da obra; percepção dos impactos dos alertas do SC; observações de possíveis causas dos problemas atuais, por exemplo, onde aconteceu um erro, que atividade ou qual equipe, equipamento que causou o erro; percepção de um problema futuro, por exemplo, o SC alerta que o estoque de óleo diesel está baixo e o engenheiro sabe quais materiais são vitais para a obra e pode interferir na aquisição rápida destes; entendimento do cenário previsto para a obra e a realidade encontrada; e diversos outros conhecimentos.

Essas informações e conhecimentos são oriundos das bases de dados e das bases de conhecimentos dos sistemas das cidades, prefeituras e organizações formais e informais do município. Esses recursos inovadores podem propiciar decisões no que diz respeito à gestão municipal com parâmetros subsidiam as ações dos gestores municipais, dos servidores e dos munícipes. Esses sistemas podem fornecer visões macro do município com a utilização do seu zoneamento urbano e também das intervenções de atividades dentro de determinadas prioridades de atuação. Essas atuações ou ações para facilitar a gestão municipal podem estar descritas nos planejamentos municipais (planejamento estratégico municipal, plano diretor da cidade e plano plurianual municipal) e armazenadas nos sistemas de informação e nos sistemas de conhecimentos da cidade ou prefeitura.
Para atender os preceitos e aplicações da NPM e para facilitar a agilidade nos processos municipais são requeridas diversas funções municipais e ações organizacionais conjuntas para resolver os problemas do município. Nesse sentido, os sistemas propostos (de informação e de conhecimentos) podem contribuir significativamente com as cidades, prefeituras e organizações (privadas ou públicas) e com integração desses processos complexos. Nesse sentido, o mercado imobiliário das cidades também se relaciona com a NPM à medida em que a gestão municipal contextualiza as necessidades habitacionais dos cidadãos; que elabora orçamentos imobiliários baseados em resultados financeiros da prefeitura contemplando a demanda local; e que realiza a reestruturação, reengenharia, reinvenção, realinhamento e reconceituação das carências imobiliárias da cidade dentro dos seus limites financeiros e legais. As relações da NPM com o mercado imobiliário das cidades estão mais direcionadas com o plano diretor urbano. Nesse caso, são planejadas e controladas as atividades vinculadas com a ordenação do espaço urbano, com a determinação do uso do solo local, com a utilização de estudos territoriais e de meios físicos, com planos normativos para regulamentar as ações municipais.

Dessa forma, os sistemas de informações e os sistemas de conhecimentos (por mais simples em termos de tecnologia que sejam, mas que tenham condições de armazenar dados, disponibilizar informações e compartilhar conhecimentos) podem proporcionar facilidades aos gestores municipais, aos servidores e aos munícipes que são os decisores no município. Os sistemas posicionam os decisores da realidade à qual eles devem considerar em suas decisões, o que pode garantir a efetividade das intervenções municipais a serem realizadas.

\section{Conclusão}

Este trabalho propicia ao leitor uma visão mais detalhada sobre sistemas de informação e sistemas de conhecimentos, por meio dos seus conceitos, relações e modelos descritos. Também propicia uma discussão inicial sobre os conceitos e as aplicações dos preceitos da New Public Management (NPM) relacionados com a gestão municipal com o suporte dos sistemas propostos (Figura 3) e dos seus respectivos Modelos de Informações Organizacionais e Mapas de Conhecimentos. Esses modelos e mapas contêm respectivamente a descrição das informações oportunas e dos conhecimentos personalizados necessários para conduzir, controlar e gerir as cidades e prefeituras.

Como os municípios estão enfrentando dificuldades quando do projeto e da execução de serviços públicos 
municipais, os sistemas de informação e os sistemas de conhecimentos podem contribuir de forma diferenciada e efetiva na gestão municipal. E também podem contribuir com os servidores e com os munícipes nas suas atividades cotidianas, gerenciais e estratégicas, fornecendo informações oportunas e compartilhando conhecimentos personalizados relacionados com os referidos serviços municipais.

As equipes das unidades de tecnologia da informação das prefeituras têm facilidade na modelagem de dados e no desenvolvimento de software e as equipes das unidades da administração das prefeituras têm facilidade na modelagem de procedimentos e no desenvolvimento de processos municipais. Em muitas prefeituras a modelagem de informações e o mapeamento de conhecimentos ainda é um desafio. Nesse caso a atuação do cidadão é fundamental, pois ele pode relatar quais as informações que necessita para participar social e civicamente do município. As cidades e prefeituras que modelam informações e também mapeiam conhecimentos e compartilham as suas melhores práticas, podem ser consideradas cidades, prefeituras e organizações que inovam nas suas ferramentas de gestão municipal.

Como pôde ser observado, a partir do capital intelectual dos decisores (gestores municipais, servidores e munícipes) o modelo proposto de sistemas de conhecimentos (Figura 3) quando competentemente desenvolvido e disponibilizado nas cidades e prefeituras, pode gerar informações e compartilhar conhecimentos peculiares de serviços municipais. Principalmente pela variedade de detalhes nas suas complexas atividades com múltiplos atores sociais (e stakeholders) tais como cidadãos, funcionários, empreiteiros, fornecedores, comunidades e outros grupos de interesses envolvidos. Tais informações e conhecimentos devem ser direcionados aos problemas e as soluções pertinentes ao município, visando o aumento da qualidade de vida de seus munícipes.

Dessa forma, os municípios também poderão aplicar mais efetivamente os conceitos e os preceitos da NPM utilizando as informações oportunas e os conhecimentos personalizados dos serviços municipais projetados e em execução. Os serviços projetados fazem parte do modelo de gestão do município, das estratégias do planejamento estratégico municipal e dos planos de ações constantes do plano diretor das cidades e do plano plurianual do município. Esse desafio deve superar os planos dos governos originalmente destinados apenas aos quatro anos de mandato. Ao superar esses anos predefinidos, aumenta-se a multiplicação das informações, a proliferação de práticas adequadas e consequientemente o compartilhamento dos conhecimentos entre os gestores municipais, os servidores e os munícipes.
O objetivo deste artigo estava direcionado nas relações entre as teorias e práticas dos sistemas de informação, da tecnologia da informação e dos sistemas de conhecimentos, contextualizando a NPM como um modelo de gestão municipal que pode contribuir com as cidades e prefeituras. $\mathrm{O}$ modelo proposto (Figura 3) e as argumentações descritas validam essas relações e reiteram a relevância dessas integrações para as contribuições efetivas na gestão municipal.

Os resultados auferidos nesse projeto foram expressos em suas contribuições. A contribuição deste trabalho para o meio acadêmico está relacionada com o desenvolvimento metodológico do modelo sugerido (Figura 3), o qual poderá agregar novos valores e conhecimentos aos alunos envolvidos com estudos em sistemas de informação, tecnologia da informação, gestão do conhecimento e sistemas de conhecimentos. A contribuição para as cidades e prefeituras está na disponibilidade de um modelo que pode se transformar num protótipo (ou software) de sistema de informação e sistema de conhecimentos para auxiliar as decisões e ações cotidianas dos gestores municipais, dos servidores e dos munícipes.

Por meio do modelo sugerido, ficou demonstrado o papel relevante e estratégico dos sistemas de informação, dos sistemas de conhecimentos e da tecnologia da informação, principalmente pela possibilidade da geração e uso de informações oportunas e do compartilhamento de conhecimentos personalizados dos gestores municipais, servidores e munícipes nas cidades e prefeituras. Também se observa que se os referidos sistemas forem utilizados corretamente, poderão contribuir na gestão dos serviços municipais e conseqüentemente, na realização dos seus objetivos, projetos, estratégias e ações públicas municipais.

A principal limitação deste trabalho está relacionada com a descrição e organização do conhecimento tácito dos gestores municipais, dos servidores e dos munícipes. Os principais trabalhos futuros estão direcionados para o desenvolvimento e implantação de softwares de sistemas de conhecimentos aplicados na gestão pública municipal.

\section{Referências}

ALTER, L. S. Information systems: a management perspective. Menlo Park, California: Benjamin \& Cummings, 2. ed., 1996.

BAKOS, J. Y.; TREACY, M. E. Information technology and corporate strategy: a research perspective. MIS Quarterly, p.107-119, June 1986.

BARCLAY, R.; MURRAY, P. C. What is knowledge 
management? Media Access. Disponível em <http:// www.media-access.com/whatis.html\#top>. Acesso em: 15 novembro 1999.

BARZELAY, M. The New Public Management: improving research and policy dialogue. Regents of the University of California, 2001.

BOAR, B. H. The art of strategic planning for information technology: crafting strategy for the 90s. USA: John Wiley \& Sons, 1993.

BROADBENT, M.; WEILL, P.; CLAIR, D. S. The implications of information technology infrastructure for business process redesign. MIS Quarterly, Minneapolis, v. 23, p. 159-182, June 1999.

CARVALHO, R. B. Aplicações de softwares de gestão do conhecimento: tipologia e usos. 2000. $144 \mathrm{f}$.

Dissertação (Mestrado em Ciência da Informação) Universidade Federal de Minas Gerais, Belo Horizonte.

CIBORRA, C. A platform for surprises: the organizational of global technology strategy at Olivetti. In: BASKERVILLE, R. et al. Transforming organizations with information technology. Amsterdam: IFIP Transactions, 1994.

CUNHA, M. A. V. C. Portal de serviços públicos e de informação ao cidadão: estudo de casos no Brasil. 2000. 172 f. Tese (Doutorado em Administração). Universidade de São Paulo - FEA/USP. São Paulo.

DAVENPORT, T:; PRUSAK, L. Conhecimento empresarial: como as organizações gerenciam seu capital intelectual. Rio de Janeiro: Campus, 1998.

DENHARDT, R. B.; DENHARDT, J. V. The new public service: serving rather than steering. Public Administration Review. Washington, v. 60, p. 549-560, Nov/ Dec 2000.

FLEURY, M. T. L.; OLIVEIRA Jr., M. (Org.). Gestão estratégica do conhecimento: integrando aprendizagem, conhecimento e competências. São Paulo: Atlas, 2001.

FREITAS, H. M. R.; BECKER, J. L.; KLADIS, C. M. et al. Informação e decisão: sistemas de apoio e seu Impacto. Porto Alegre: ORTIZ, 1997.

FURLAN, J. D.; IVO, I. M.; AMARAL, F. P. Sistemas de informação executiva (EIS). São Paulo: Makron Books, 1994.

GIL, A. C. Métodos e técnicas de pesquisa social. 5. ed. São Paulo: Atlas, 1999.
HEEKS, R. Reinventing government in the information age. International Practice in IT-Enabled Public Sector Reform. London: Routledge, 2001.

HENDERSON, J. C.; VENKATRAMAN, N. Strategic alignment: leveraging information technology for transforming organizations. IBM Systems Journal, v. 32, n. 1, p. 4-16, 1993.

JOÃO, B. N. Das competências essenciais às estratégias baseadas no conhecimento. In: ENCONTRO ANUAL DA ANPAD, 25., 2001, Campinas. Anais... Campinas: ANPAD, 2001.

JONES, L. R.; THOMPSON, F. Um modelo para a nova gerência pública. Revista do Serviço Público. v. 51, n. 1, p. 41-79, 2000.

LAUDON, K. C.; LAUDON, J. P. Sistemas de informação. 4. ed. Rio de Janeiro: LTC, 1999.

LUFTMAN, J. N.; BRIER, T. Achieving and sustaining business-IT alignment. California Management Review, Berkeley, v. 42, p. 109-122, Fall 1999.

MARCONI, M.A.; LAKATOS, E. M. Técnicas de pesquisa. 3. ed. São Paulo: Atlas, 1996.

MARKUS, L. M. Toward a theory of knowledge reuse: types of knowledge reuse situations and factors in reuse success. Journal of Management Information Systems, Armonk, v. 18, p. 57-93, Summer 2001.

McFARLAN, F. W. Information technology changes the way you compete. Harvard Business Review, v. 3, n. 62, p. 98-103, 1984.

MINTZBERG, H.; QUINN, J. B. O processo da estratégia. 3. ed. Porto Alegre: Bookman, 2001.

NACHMIAS, D.; NACHMIAS, C. Research methods in the social sciences. 3. ed. New York: St. Martin's Press, 1987.

NOLAN, R. L. Note on information technology and strategy. Boston: Harvard Business School, 1993.

NONAKA, I.; TAKEUCHI, H. Criação do conhecimento na empresa: como as organizações japonesas geram a dinâmica da inovação. Rio de Janeiro: Campus, 1997.

NORTON, P. Introdução à informática. São Paulo: Makron Books, 1996.

O'BRIEN, J. A. Sistemas de Informação e as decisões gerenciais na era da Internet. São Paulo: Saraiva, 2001. 
OSBORNE, D.; GAEBLER, T. Reinventing

government: how the entrepreneurial spirit is transforming the public sector. Reading, MA: Addison-Wesley, 1992.

PEREIRA, R. O.; REZENDE, D. A.; ABREU,A. F. Gestão do conhecimento com apoio dos recursos de sistemas de informação e tecnologias emergentes. In: ENCONTRO NACIONAL DEENGENHARIADE PRODUÇÃO, 20., 2000, São Paulo. Anais... São Paulo: ENEGEP, 2000.

PORTER, M. E.; MILLAR, V. E. How information gives you competitive advantage. Harvard Business Review, v. 63, n. 4, p. 149-160, Jul./Aug. 1985.

PRAHALAD, C. K.; HAMEL, G. The core competence of the corporation. Harvard Business Review, p.79-91, May-June 1990.

REZENDE, D. A. Engenharia de software e sistemas de informação. Rio de Janeiro: Brasport, 1999.

REZENDE, D. A. Sistemas de informações organizacionais: guia prático para projetos em cursos de administração, contabilidade e informática. São Paulo: Atlas, 2005.

REZENDE, D. A. Tecnologia da informação integrada à inteligência empresarial: alinhamento estratégico e análise da prática nas organizações. São Paulo: Atlas, 2002.

REZENDE, D. A.; ABREU, A. F. Tecnologia da informação aplicada a sistemas de informação empresariais. 3. ed. São Paulo: Atlas, 2003.

REZENDE, D. A.; CASTOR, B. V. J. Planejamento estratégico municipal: empreendedorismo participativo nas cidades, prefeituras e organizações públicas. Rio de Janeiro: Brasport, 2005.

RILEY, T. B. E-government vs. E-governance: examining the differences in a changing public sector climate. International Tracking Survey Report '03, n. 4, May 20, 2003. Disponível em <http://www.electronicgov.net/pubs/ research_papers/tracking03/IntlTrackRptMay03no4.pdf>. Acesso em: 15 julho 2003.

ROCKART, J. F.; MORTON, M. S. S. Implications of changes in information technology for corporate strategy. Interfaces, v. 14, n. 1, p. 84-95, Jan./Feb. 1984.

ROESCH, S. M. A. Projeto de estágio e de pesquisa em administração: guia para estágios, trabalhos de conclusão, dissertação e estudos de caso. 2. ed. São Paulo: Atlas, 1999.

RUEDIGER, M. A. Governo Eletrônico e Democracia: uma análise preliminar dos impactos e potencialidades na gestão pública. In: ENCONTRO ANUAL DAANPAD, 26., 2002, Salvador. Anais... Salvador: ANPAD, 2002.

SANTOS, A. R.; PACHECO, F. F.; PEREIRA, H. J.; BASTOS Jr., P. A. (Org.). Gestão do conhecimento: uma experiência para o sucesso empresarial. Curitiba: Champagnat, 2001.

STAIR, R. M. Princípios de sistemas de informação: uma abordagem gerencial. 2. ed. Rio de Janeiro: LTC, 1998.

STEWART, T. A. Capital Intelectual: a nova vantagem competitiva das organizações. 2. ed. Rio de Janeiro: Campus. 1998.

SVEIBY, K. E. A nova riqueza das organizações: gerenciando e avaliando patrimônios de conhecimento. Rio de Janeiro: Campus, 1998.

TORNATZKY, L. G.; FLEISCHER, M. The process of technological innovation. Toronto: Lexington Books, 1990.

TURBAN, E.; MCLEAN, E.; WETHERBE, J. Information technology for management: improving quality and productivity. New York: John Wiley \& Sons, 1996.

TURTHIL, G. S. Knowledge engineering: concepts and pratices for knowledge-based system. Blue Ridge Summit, PA: Tab Books, Inc, 1990.

VIGODA, E. From responsiveness to collaboration: governance, citizens, and the next generation of public administration. Public Administration Review. Washington, v. 62, p. 527-541, Sep/Oct, 2002.

WAISANEN, B. The future of e-government: technologyfueled management tools. Washington: Management. v. 84, p. 6-10. Jun 2002.

YIN, R. K. Case study research. London: Sage Pub., 1994. 
